\title{
Benefit Model of Knowledge Sharing Behavior
}

\author{
Jianying Zhang \\ Institute of Business Administration, South China University of Technology, Guangzhou, China \\ Email: 15099995896@163.com
}

How to cite this paper: Zhang, J.Y. (2017) Benefit Model of Knowledge Sharing Behavior. Open Journal of Social Sciences, 5, 161169. https://doi.org/10.4236/jss.2017.58013

Received: July 27, 2017

Accepted: August 11, 2017

Published: August 14, 2017

Copyright $\odot 2017$ by author and Scientific Research Publishing Inc. This work is licensed under the Creative Commons Attribution International License (CC BY 4.0).

http://creativecommons.org/licenses/by/4.0/

\begin{abstract}
This article has combed the knowledge sharing, the staff creativity and the staff psychological security related literature, has explored the staff knowledge sharing behavior to own creativity influence, proposed "the Knowledge sharing benefit model", and on this foundation further studies the psychological security to this model influence.
\end{abstract}

\section{Keywords}

Employee Knowledge Sharing Behavior, Employee Creative Staff, Psychological Security

\section{Introduction}

The employee knowledge sharing behavior is a hot topic in the Western Knowledge management theory since the mid 1990s, and this behavior has become a new field of knowledge management theory. Employee knowledge sharing behavior refers to the exchange and discussion of knowledge between employees and outside employees in the organization through various channels [1]. Employee knowledge sharing can provide employees with more opportunities to learn from each other [2] and may also improve organizational performance [3]. Therefore, in the era of knowledge economy, the study of employee knowledge sharing behavior becomes more and more important.

In the academic circle, the influence mechanism of employee knowledge sharing on employees and organizations has been explored. Among them, because staff creativity is the cornerstone of organizational competitiveness, the promotion of staff creativity can more effectively enhance organizational competitiveness [4], so the employee knowledge sharing behavior on staff creativity Impact Mechanism is one of the focuses of domestic and foreign researchers. Many scholars have put forward the idea that employee's knowledge-sharing behavior can promote the promotion of colleagues' creativity [5] [6]. However, 
knowledge-sharing behavior is an interactive behavioral process [7], an interactive behavioral process involving multiple behavioral subjects, so that knowledge-sharing behavior should have an impact on multiple behavioral subjects. However, it is found that the research direction on the impact of knowledge sharing behavior on staff creativity is mostly focused on the influence of the knowledge sharing behavior of one employee on the creativity of another employee, and the research just ignores the angle that knowledge-sharing behavior affects the knowledge-sharing creativity. Therefore, this article attempts to explore the mechanism of employee's knowledge sharing behavior to the employee's own creativity, which will help to understand the role of knowledge sharing behavior more comprehensively, and avoid the effect of neglecting knowledge-sharing in the study of knowledge sharing behavior. In order to explain the viewpoint of this paper more clearly, the subject of knowledge is called knowledge-sharing, and the subject of receiving knowledge is called Knowledge receiver.

\section{Theory and Hypothesis}

\subsection{The Impact of Knowledge-Sharing Behavior on the Creativity of Knowledge-Sharing}

In the traditional theory of organization economy, the basic assumption for human is that individuals care about their own interests [8]. For employees, their knowledge-sharing behavior will cause the knowledge diffusion, the staff no longer have the knowledge of uniqueness, thus the employee's own interests are impaired [8], and the willingness or behavior of unwilling to share his knowledge with others is obvious [9] Once the employee has the knowledge as his or her own personal assets, and the asset can give the individual an advantage over others. The theory of social exchange provides a theoretical basis for solving this problem.

The theory of social exchange began to rise in the late 50, using the theory of economics, sociology and psychology to explore individual behavior from microcosmic point of view [10], which has become one of the important theories in organizational behavior theory. Blau and other people think that any exchange relationship existing in the organization or group can be divided into economic exchange relations and social exchange relations. Under the economic transaction relation, the individual and the individual transaction's establishment is based on individual to own short-term correlation benefit appraisal. But under the social exchange relation, the establishment of the transaction between individual and individual is not based on the individual's own short-term related benefit evaluation, the individual short-term related interest to the transaction decision-making influence degree weight reduces, the bilateral transaction establishment more is based on the individual to the transaction benefit income anticipation. As an important angle of view of interpersonal relationship, the theory of Social exchange of domestic scholars thinks that interpersonal interac- 
tion is based on social exchange, and the relevant activities are exchanged at the same time under this kind of social exchange, and the valuable related resources are also traded. In the organization, the employee is the practitioner of the knowledge-sharing behavior, the knowledge-sharing behavior among the employees is the knowledge-sharing and the knowledge-demand person, while the knowledge-sharing behavior includes acquiring knowledge and providing knowledge [7]. Therefore, the knowledge sharing behavior is interactive, Cerne and other people think that the knowledge sharing behavior among employees is a concrete manifestation of the social exchange behavior between employees [11].

In the theory of social exchange, the logic of the success of the dominant exchange lies in the principle of reciprocity, which is the precondition of social exchange and the basic principle of social exchange [12]. The principle of reciprocity refers to a series of guidelines recognized by all parties in the course of exchange, that is, when one party provides assistance or resources to the other, the latter is obligated to repay the person who has given assistance [12]. Gouldner [12] and others believe that individuals can generate positive emotions from their own reciprocal acts, and that individuals also have negative emotions, such as guilt, because they are not able to perform reciprocal duties. Bartol and Srivastava, who think that through this reciprocal act of mutual giving or reciprocal exchange, individuals can connect with each other in the social emotional network, and once the social emotional network is formed, the individual, in order to maintain and strengthen this social emotional connection, will provide the implicit rewards of admiration, appreciation and friendliness, and will also provide the explicit remuneration of material rewards [13]. Therefore, under the principle of reciprocity, when an individual feels that he has benefited from an act, which is the beneficiary of the act, the individual will have a psychological pressure to return the interest to the other subjects initiating such behavior, creates a sense of return benefit, which may give rise to an act of reward for an individual receiving a benefit, thus forming a reciprocal mechanism for giving and rewarding, and establishing a continuing good social Exchange [14]. And the principle of reciprocity is also prevalent in various cultures of society, as the western proverb "You scratch me back and I'll scratch yours", the Chinese old saying "to the peach, reported to Lee." Especially in China, the principle of reciprocity is part of Chinese traditional philosophy and values [15].

Employee knowledge-sharing behavior as a social exchange between employees [11], in the course of this behavior, knowledge-sharing and knowledgerecipients are actually exchanging knowledge resources. Social exchange theory holds that in this kind of social exchange behavior, the paying person makes the behavioral decision not based on the short-term related interests which may be obtained, but is based on the expectation that the other party will reciprocate in some form in the future as the main consideration. Similarly, the principle of reciprocity plays an important role in the social exchange of knowledge-sharing behavior, and the principle of reciprocity makes both sides willing to take risks 
and exchange knowledge resources [12]. Specifically, when employee a takes a knowledge-sharing behavior with employee $\mathrm{B}$, that is, employee a provides knowledge to employee B. Employee B perceives the behavior of employee a providing knowledge, at this time, the principle of reciprocity takes effect and employee B rewards the behavior of employee a, such as feedback and providing relevant knowledge, questioning the knowledge content provided by employee $\mathrm{A}$ or expressing his or her relevant views. Similarly, based on the principle of reciprocity, employee A will also make similar returns on the knowledge provided by Employee B.

According to the definition of creativity proposed by Shalley, the necessary condition for an idea or countermeasure to be judged as creative is that this idea and countermeasure is novel and useful [16]. Then, at work, employees can create their own creativity by creating a new idea and implementing the idea at work, or by proposing a new process to embody creativity, and by creating a new idea for the combination of existing ideas. Therefore, creativity does not exist only in certain jobs, but in the work of employees in different jobs. and different staff embodies the level of creativity is also different. A small change in the existing ideas, and a new form of reuse, is creativity. In the same way, a radical change creates a huge breakthrough that is creative. These are creativity, just different degrees of creativity. Zhou and George think that a major breakthrough in the workflow of a small change to science and technology is creativity, it is not only the work of scientists, researchers, engineers and so on that can embody creativity, but with the right conditions, employees of any job can show their creativity [17]. The creativity of this paper includes various levels of creativity, and is not limited to a few specific types of work. Scholars have conducted a great deal of research on the theme of employee's knowledge-sharing behavior which influences the creativity of employees [5] [6] believes that through knowledge-sharing behavior, employees can link or regroup the knowledge and ideas that have not been linked in the past, creating new knowledge, solving new problems, and boosting creativity [18]. The main conclusion is that the knowledge-sharing behavior of some employees can promote the creativity of other employees [5] [18].

Creativity is an important part of interpersonal interaction [19]. Creative ideas and responses are often the result of a combination of different perspectives and perspectives in social interactions [20], and the process of creative ideas and responses is also a process of interpersonal interaction [21]. The employee knowledge sharing behavior is a kind of social interaction behavior, in this interaction process, the two sides exchange the valuable knowledge, the individual contact the optional plan and the related information more, the more likely enhances the creativity. The amount of knowledge accumulated by employees has an important influence on the strength of creativity, and the knowledge accumulation is closely related to the degree of knowledge Sharing [22]. Thus, creativity depends, to a certain extent, on the knowledge provided by others. The different perspec- 
tives and perspectives that individuals are exposed to during social interactions may enhance their creativity [23].

In the process of the social exchange behavior of knowledge sharing, when the knowledge-sharing provider provides relevant knowledge to the knowledge recipient, the knowledge receiver can acquire and accumulate more knowledge, which has a positive impact on the creativity of the Knowledge recipient [5] [6]. And based on the principle of reciprocity, knowledge recipients respond to knowledge-sharing, knowledge recipients also provide knowledge to knowledgesharing, and knowledge-sharing can gain knowledge from knowledge recipients, and the process of interaction enables both sides to reach each other's viewpoints [7]. Therefore, the creativity of both sides has a positive impact.

The social exchange behavior of knowledge sharing acts as a social interaction between knowledge-sharing and knowledge receivers [24], \$time, Perry-smith believes that social interaction can promote creative Ascension [5]. Social interaction as a cognitive process, through this cognitive process can be a solution to the problem, because through social interaction, employees can access to new knowledge, new knowledge including problem-solving knowledge and related experience, employees can also deepen their understanding of new and prior knowledge, which is also a potential reflection of their knowledge and knowledge of how to use them, and when employees have more field-related knowledge and better understanding of these knowledge, they can enhance the problem-solving ideas and abilities, Enhance employee creativity [5]. Knowledge has an important impact on creativity [23], and the creative ideas of employees often come from new fusion of different viewpoints and perspectives [24], and the fusion of different viewpoints occurs in this process of mutual communication. Therefore, this paper proposes a "knowledge-sharing benefit model" for knowledge-sharing behavior to promote the promotion of knowledge-sharing's own creativity (Figure 1), and the role of knowledge-sharing and knowledge-recipient is changing continuously in the social exchange behavior of knowledge sharing. When employee a provides knowledge to employee $\mathrm{B}$, employee a plays the role of knowledge-sharing, employee B plays the role of the knowledge-recipient, and knowledge-sharing does not diminish knowledge-sharing because of the characteristics of knowledge. When the knowledge receiver receives knowledge from knowledge-sharing, the knowledge of the recipient of knowledge increases, and the knowledge-sharing behavior of knowledge-sharing promotes the knowledge recipient's creativity [5] [6] and knowledge sharing as a social Exchange Act, the principle of reciprocity plays an important role in which the recipient of knowledge is rewarded for the behavior of the knowledge-sharing person [12], employee B will be a share of the knowledge of employees to make feedback, employee B will also be their views and related knowledge to the employee a, at this time, employee B plays the role of knowledge-sharing, employee a plays the role of the knowledge-recipient. It is in the process of changing the roles of both sides that both sides have gained different viewpoints and perspec- 


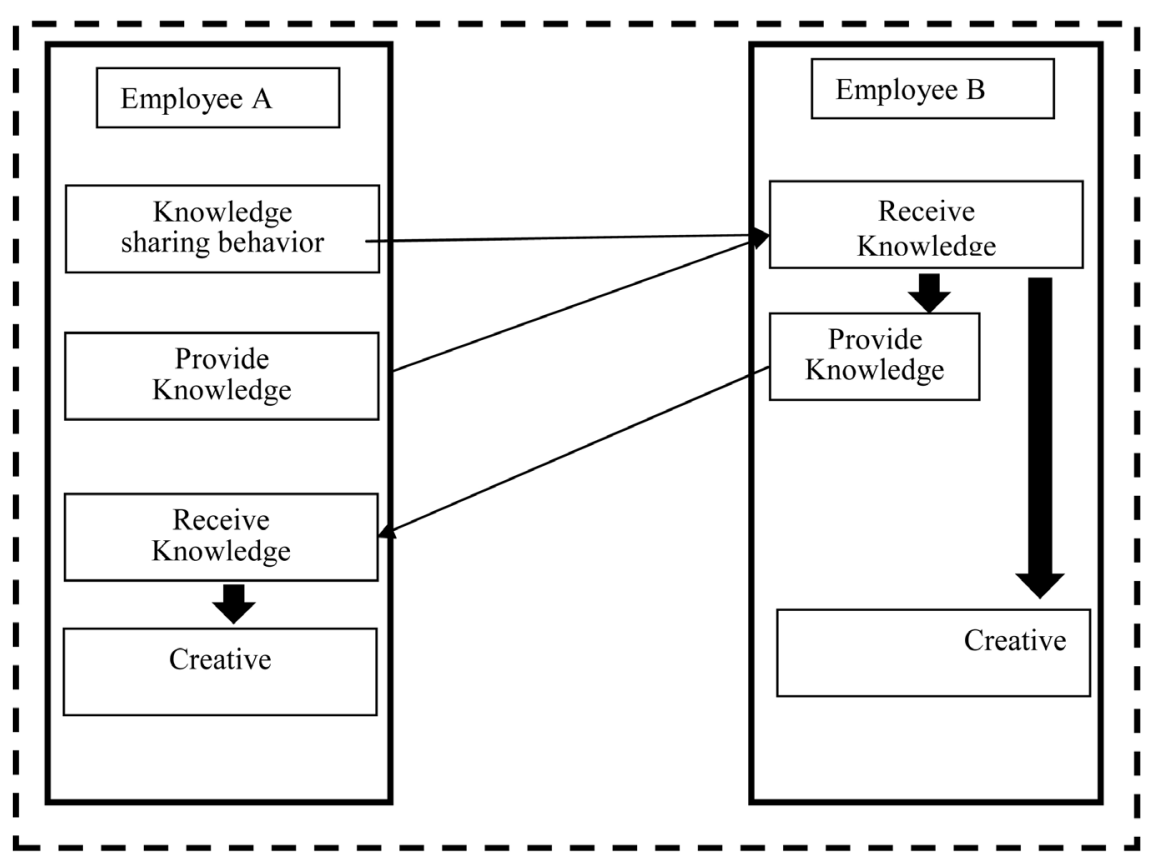

Figure 1. Knowledge-sharing benefit model.

tives relative to themselves. Therefore, when employee a has a knowledge-sharing behavior with employee $B$, it can not only improve the creativity of employee $B$, but also enhance the creativity of employee A.

Based on the above analysis, put forward.

Hypothesis 1: Knowledge-sharing behavior has a significant positive relationship with the creativity of knowledge-sharing.

\subsection{The Moderating Effect of Psychological Security}

In the field of organizational management and social psychology, the psychological security of employees provides a new perspective for the research of employee's knowledge sharing behavior and employee's creativity, Kahn that employees' psychological security is a characteristic of employees, which reflects the individual's psychological state and self perception [25]. On this basis, Kahn [25] believes that psychological security affects individual internal motivation and the psychological state of shaping individual role, when employees experience more psychological security, they get a higher level of participation [25], and involve employees in more knowledge-sharing behaviors [17].

Employees are exposed to a variety of risks in their work, which have a significant impact on individual perceptions, emotions and behavior. Each enterprise information or knowledge as a valuable resource, the object of knowledge sharing behavior is this kind of valuable resources, so employee knowledge sharing behavior carries a certain risk [8]. This paper argues that, under such measures as the elimination mechanism of enterprises, employees will protect their resources through a series of measures, so that their own interests can not be harmed. In the case of a certain level of risk, when the employee's psychological 
security to the other side is low, it will withdraw from activities that require their own valuable resources [26], therefore, the lower the level of psychological security of each other, the less interactive sharing of activities, sharing of information and knowledge, according to social exchange theory, the less feedback will be. The higher the level of psychological security of employees, the knowledge sharing behavior can promote the creativity of the knowledge-sharing.

Based on the above analysis, put forward.

Assumption 2: The employee's knowledge-sharing behavior has a positive moderating effect on the employee's own creativity, and the knowledge-sharing person with high psychological security has more obvious positive regulation to the promotion of their own creativity.

\section{Analysis and Revelation of the Research Results}

From an individual point of view, to realize knowledge sharing and transfer between different individuals, there is an important link, that is, to enhance the willingness of individuals to participate in knowledge-sharing behavior, to make it more spontaneous participation [1]. The knowledge sharing behavior has the positive function to the organization or the individual employee, and it shows that the knowledge sharing behavior plays an important role in the sustainable development of the Organization. But the current study focuses only on objects that are outside the knowledge-sharing group. If an individual feels that an action is beneficial to itself and tends to do so, if it is detrimental to itself, it avoids such behavior, and if knowledge-sharing behavior has only a negative impact on the knowledge-sharing, then the knowledge-sharing behavior of the organization can be greatly reduced or even close to disappearing. However, the fact is that knowledge-sharing behavior has a lot of existence, and it shows that knowledge-sharing behavior has positive and beneficial side. Therefore, enterprise managers should take measures to improve the positive impact, so that employees can more actively share knowledge.

This study has the following theoretical contributions: first, to build a "knowledge sharing benefit model", this model is from a brand-new perspective to study the income of knowledge-sharing behavior-the knowledge-sharing itself, it expands the research scope of knowledge management literature, fills up the blank of literature, and second, the knowledge-sharing behavior as an interactive process, The psychological security of knowledge-sharing has a moderating effect on knowledge-sharing behavior and the creativity of knowledge-sharing.

This research also has the following enlightenment to the management practice: first, based on previous research and the conclusion of this paper, knowledge sharing behavior can not only improve the creativity of the knowledge recipient, but also improve the creative ability of the knowledge-sharing, therefore, it is necessary to encourage the knowledge sharing behavior in the organization, especially in the innovative organization which needs the staff to have the high level of innovation Second, knowledge-sharing behavior can have a positive impact on knowledge-sharing and knowledge-receivers, and the psychological se- 
curity of knowledge-sharing will affect this positive effect, so the managers of enterprises need to take some measures to promote the psychological security among employees.

Although this research has obtained some reference value to the enterprise management theory and the practice, but still has some insufficiencies: first, this research's forecast variable all is at the same time point forecast, in the strict sense still can not completely reveal the causal relationship between job insecurity and staff creativity, in addition, the data of this study take the staff self-filling questionnaire, although the independence of the variable is tested by the distinction validity test, it is inevitable that the social approval problem will arise, resulting in greater deviations [27]. Secondly, knowledge is divided into tacit knowledge and explicit knowledge, but this paper does not classify the knowledge, but it studies it with a whole. Thirdly, knowledge-sharing behavior has a very complex impact on the creativity of knowledge-sharing, and needs to be further explored. Therefore, the future can be considered in the following ways. Firstly, the object knowledge of knowledge sharing behavior is classified to explore the function of different knowledge types in this model, and secondly, to probe into its mechanism and influencing factors.

\section{References}

[1] Hansen, S. and Avital, M. (2005) Share and Share Alike: The Social and Technological Influences on Knowledge Sharing Behavior. Sprouts. Working Papers on Information Environments, Systems and Organizations, 5, 1-19.

[2] Huber, G.P. (1991) Organizational Learning: The Contributing Processes and the Literatures. Organization Science, 2, 88-115. https://doi.org/10.1287/orsc.2.1.88

[3] Hansen, M.T. (2002) Knowledge Networks: Explaining Effective Knowledge Sharing in Multiunit Companies. Organization Science, 13, 232-248.

https://doi.org/10.1287/orsc.13.3.232.2771

[4] Dino, R.N. (2015) Crossing Boundaries: Toward Integrating Creativity, Innovation, and Entrepreneurship Research through Practice. Psychology of Aesthetics, Creativity, and the Arts, 9, 139. https://doi.org/10.1037/aca0000015

[5] Perry-Smith, J.E. (2006) Social yet Creative: The Role of Social Relationships in Facilitating Individual Creativity. Academy of Management Journal, 49, 85-101. https://doi.org/10.5465/AMJ.2006.20785503

[6] Sharon, W. and Kelly, H. (2006) A Multi-Theoretical Model of Knowledge Transfer in Organizations: Determinants of Knowledge Contribution and Knowledge Reuse. Journal of Management Studies, 43, 141-173.

[7] Reinholt, M., Pedersen, T. and Foss, N.J. (2011) Why a Central Network Position Isn't Enough: The Role of Motivation and Ability for Knowledge Sharing in Employee Networks. Academy of Management Journal, 54, 1277-1297. https://doi.org/10.5465/amj.2009.0007

[8] Kim, W.C. and Mauborgne, R. (1998) Procedural Justice, Strategic Decision Making, and the Knowledge Economy. Strategic Management Journal, 19, 323-338. https://doi.org/10.1002/(SICI)1097-0266(199804)19:4<323::AID-SMJ976>3.0.CO;2-F

[9] Orr, J. (1990) Sharing Knowledge, Celebrating Identity: War Stories and Community Memory in a Service Culture. Collective Remembering Memory in Society. 
[10] Homans, G.C. (1958) Social Behavior as Exchange. American Journal of Sociology, 63, 597-606. https://doi.org/10.1086/222355

[11] Cerne, M., Nerstad, C., Dysvik, A., et al. (2014) What Goes around Comes around: Knowledge Hiding, Perceived Motivational Climate, and Creativity. Academy of Management Journal, 57, 172-192. https://doi.org/10.5465/amj.2012.0122

[12] Gouldner, A.W. (1960) The Norm of Reciprocity: A Preliminary Statement. American Sociological Review, 25, 161-178. https://doi.org/10.2307/2092623

[13] Bartol, K.M. and Srivastava, A. (2002) Encouraging Knowledge Sharing: The Role of Organizational Reward Systems. Journal of Leadership \& Organizational Studies, 9, 64-76. https://doi.org/10.1177/107179190200900105

[14] Falk, B.A. and Fischbacher, U. (2010) A Theory of Reciprocity. Games and Economic Behavior, 54, 2.

[15] Jia, L., Song, J., Li, S., et al. (2007) Leadership Style and Staff Working Attitude: Reciprocity and Trust Intermediary Role of the Empirical Study. China Management Research, 1, 574-605.

[16] Shalley, C.E. and Zhou, J. (2008) Handbook of Organizational Creativity. Lawrence Erlbaum Associates, New York.

[17] Zhou, J. and George, J.M. (2003) Awakening Employee Creativity: The Role of Leader Emotional Intelligence. The Leadership Quarterly, 14, 545-568.

[18] Gong, Y., Kim, T., Lee, D., et al. (2013) A Multilevel Model of Team Goal Orientation, Information Exchange, and Creativity. Academy of Management Journal, 56, 827-851. https://doi.org/10.5465/amj.2011.0177

[19] Woodman, R.W. and Griffin, R.W. (1993) Toward a Theory of Organization Creativity. Academy of Management Review, 18, 293-321.

[20] Patel, M.S., Chaikof, E.L., Ferrara, G., et al. (2016) Promoting Creativity and Innovation in a Structured Learning Environment. Annals of Surgery, 264, 39-40. https://doi.org/10.1097/SLA.0000000000001658

[21] Perry-Smith, J.E. and Shalley, C.E. (2002) The Social Side of Creativity: A Static and Dynamic Social Network Perspective. Academy of Management Review, 28, 89-106.

[22] Rigolizzo, M. and Amabile, T. (2015) Entrepreneurial Creativity: The Role of Learning Processes and Work Environment Supports. The Oxford Handbook of Creativity, Innovation, and Entrepreneurship, 61.

[23] Amabile, T.M. (1997) Motivating Creativity in Organizations: On Doing What You Love and Loving What You Do. California Management Review, 40, 39-58. https://doi.org/10.2307/41165921

[24] Hammond, M.M., Neff, N.L., Farr, J.L., et al. (2011) Predictors of Individual-Level Innovation at Work: A Meta-Analysis. Psychology of Aesthetics, Creativity, and the Arts, 5, 90. https://doi.org/10.1037/a0018556

[25] Kahn, W.A. (1990) Psychological Conditions of Personal Engagement and Disengagement at Work. Academy of Management Journal, 33, 692-724. https://doi.org/10.2307/256287

[26] König, C.J., Debus, M.E., Häusler, S., et al. (2010) Examining Occupational Self-Efficacy, Work Locus of Control and Communication as Moderators of the Job Insecurity-Job Performance Relationship. Economic and Industrial Democracy, 31, 231-247. https://doi.org/10.1177/0143831X09358629

[27] Adams, S.A., Matthews, C.E., Ebbeling, C.B., et al. (2005) The Effect of Social Desirability and Social Approval on Self-Reports of Physical Activity. American Journal of Epidemiology, 161, 389-398. https://doi.org/10.1093/aje/kwi054 
Submit or recommend next manuscript to SCIRP and we will provide best service for you:

Accepting pre-submission inquiries through Email, Facebook, LinkedIn, Twitter, etc. A wide selection of journals (inclusive of 9 subjects, more than 200 journals)

Providing 24-hour high-quality service

User-friendly online submission system

Fair and swift peer-review system

Efficient typesetting and proofreading procedure

Display of the result of downloads and visits, as well as the number of cited articles Maximum dissemination of your research work

Submit your manuscript at: http://papersubmission.scirp.org/

Or contact jss@scirp.org 